followed up for more than one year after implantation and 129 have been followed up for more than two years. Femoropopliteal grafts followed up between one and two years had a patency rate of $73 \%$, and $52 \%$ of femorotibial bypasses were patent after the same period. Femoroperoneal bypasses had a patency rate of $47 \%$. These commendable results compare with those of a vein bypass-but they have been achieved by a highly experienced surgeon. Cranley and Hafner found comparable results in 63 biografts in the femoropopliteal region, ${ }^{4}$ with a patency of $73 \%$ and a $63 \%$ patency for their eight grafts followed up for that period in more distal sites. Klimach and Charlesworth, ${ }^{5}$ however, performing femorotibial bypasses in a series of 112 patients, found that only $29 \%$ of the biografts were patent after 12 months, results worse than those of vein bypasses. They did, however, include in their series patients with severe distal vessel disease, who may well have been excluded from other series. Patients with good vessels fared better. Those with only one vessel patent below the knee had $15 \%$ of grafts patent after 12 months. Those with two vessels had $28 \%$ patent and the few patients with three vessels had a patency of $49 \%$. Clearly, like all others, this conduit fails in the presence of severe arterial disease, and careful selection of patients is necessary if acceptable results are to be obtained, even in the short term.

Comparable results have been claimed in uncontrolled studies with other vascular prostheses such as velour Dacron or polytetrafluoroethylene, but there has only been one controlled trial of these prostheses versus umbilical vein. In a joint Scandinavian study Eickhoff and Buchardt-Hansen and their colleagues ${ }^{6}$ examined the fate of 104 patients having femoropopliteal bypasses for severe ischaemia in whom no saphenous vein was available. They were randomised into those who received polytetrafluoroethylene and biografts. The trial was discontinued when a significant difference was found between the two materials, umbilical vein giving better results than grafts of polytetrafluoroethylene. The patency rate was $40 \%$ in the polytetrafluoroethylene group as against $75 \%$ in the umbilical vein group. The authors acknowledge that these were very short term results and that late failures in the umbilical vein group might possibly make the grafts comparable. The results of this trial must therefore be interpreted with caution, but the report is welcome, as far too few such trials have been published.

Published data cover only the short term patency of these grafts, which is mainly dictated by the degree of distal arterial disease. Long term patency is affected by many other factors, including progression of atheroma, subintimal fibrosis at the anastomoses, and degeneration of the material. False aneurysms at anastomotic sites occur with any graft material, but true aneurysms of biological material are to be feared, as they were the downfall of the human homograft, which was widely used in the early days of vascular surgery, and of heterografts. Recently the development of true aneurysms has been reported in three biografts, each followed up for three years. ${ }^{7}$ One other graft was found to be aneurysmal on arteriography at 50 months in Cranley's series, and I recently had to replace a common femoral to anterior tibial biograft, which had been patent for two years, because of diffuse aneurysmal degeneration. These aneurysms do not appear to be associated with sepsis and, though rare, seem to be due to degeneration of the biological material and rupture of the Dacron mesh which encloses it. These early reports need not cause too much alarm, for many of these patients will die within three years of implantation, and most of the aneurysms have been replaced successfully without amputation. Clearly a longer follow up is necessary before this prosthesis is accepted unequivocally, but that caution should not be allowed to overshadow its early promise.

Consultant Surgeon,

CraWFORD W JAMIESON

St Thomas's Hospital,

London SE1 7EH

${ }^{1}$ Malone JM, Moorr WS, Goldstone J. The natural history of bilateral aortofemoral bypass grafts for ischemia of the lower extremities. Arch Surg 1975;110:1300-6.

${ }^{2}$ Szilagyi DE, Hageman JH, Smith RF, Elliot JP, Brown F, Dictz P Autogenous vein grafting in femoropopliteal atherosclerosis: the limits of its effectiveness. Surgery $1979 ; 86: 836-51$.

${ }^{3}$ Dardik H, Baier RE, Meenaghan M, et al. Morphologic and biophysical assessment of long term human umbilical cord vein implants used as vascular conduits. Surg Gynecol Obstet 1982;154:17-26.

${ }^{4}$ Cranley JJ, Hafner CD. Revascularization of the femoropopliteal arteries using saphenous vein, polytetrafluoroethylene, and umbilical vein grafts. Five- and six-year results. Arch Surg 1982;117:1543-50.

${ }^{5}$ Klimach O, Charlesworth D. Femorotibial bypass for limb salvage using human umbilical vein. Br F Surg 1983;70:1-3.

${ }^{6}$ Eickhoff JH, Hansen HJB, Brommé A, et al. A randomized clinical trial of PTFE versus human umbilical vein for femoropopliteal bypass surgery. Preliminary results. Br $\mathcal{F}$ Surg 1983;70:85-8.

7 Giordano JM, Keshishian JM. Aneurysm formation in human umbilical vein grafts. Surgery $1982 ; 91: 343-5$.

\section{Prostheses in the management of bone cancer}

Amputation is no longer the sole contribution of the surgeon to the management of bone tumours. Improvements in the design of and in methods of fixing prostheses have been combined with advances in chemotherapeutic regimens to give surgical procedures for preserving limbs affected by both primary and secondary bone tumours and by locally destructive conditions. Careful selection of patients is, however, essential: we must avoid the premature death of a patient with a satisfactory prosthesis who might have lived had he or she been treated by immediate amputation.

Total hip replacement and metallic implants fixed with methylmethacrylate cement are now well established in the management of pathological fractures secondary to metastatic carcinoma. ${ }^{12}$ In such patients treatment aims at improving the quality of life that remains, and both the demands placed on the prosthetic implant and the length of time it is expected to function satisfactorily are limited. By contrast, patients requiring resection of primary bone tumours are often young and should live with the prosthesis for many years; those with benign destructive tumours have a normal life expectancy. A substantial amount of healthy bone may need to be resected to ensure a safe margin, leaving little for the secure fixation of an endoprosthesis. At present large rapidly growing tumours and those not confined to the metaphysis of bone are quite unsuitable for prosthetic replacement, and this includes most osteosarcomas.

The first reported case of a prosthetic implant for tumour was for a recurrent giant cell tumour of the proximal femur. This was replaced with a $25 \mathrm{~cm}$ long Vitallium mould of the upper end of the femur; after operation the active motion at the hip joint was roughly three quarters of normal, though unfortunately this patient died 20 months later in cardiac failure. ${ }^{3}$ Custom built prostheses have been used to replace the femur, the hip joint, part of the pelvis, the knee joint, the humerus and shoulder joint, and parts of the ulna and radius. These are the most common sites at which primary bone tumours occur. 
Use of a limb preserving prosthesis should be considered in patients with low grade malignant bone tumours such as chondrosarcomas or parosteal osteosarcomas where there are no secondary deposits; those with benign destructive lesions of bone which are unsuitable for grafting such as fibrous dysplasia, osteolysis, and radionecrosis; and those with secondary deposits in bone after the removal of a primary tumour such as a hypernephroma. Prostheses are also valuable as a palliative procedure in patients with metastatic deposits and an impending pathological fracture. The treatment of high grade malignant bone tumours such as osteosarcoma with endoprosthetic replacement remains controversial. ${ }^{45}$ Patients with a history of proved sepsis should be assessed carefully and those with any coexisting focus of sepsis excluded-for if a prosthetic implant becomes infected it may, at best, need to be removed and at worst the patient may have to suffer a more extensive amputation than might have been needed in the first place.

The preoperative assessment should consist of a bone scan to exclude other tumours in the skeleton, a carefully planned biopsy using an incision which can be excised should a prosthetic replacement be performed, and a computed tomography scan to determine the extent of any soft tissue spread. The patient must be aware of the possibility of amputation if the insertion of a prosthesis proves to be impracticable at the time of surgery.

The tumour must be carefully removed extraperiosteally, together with the attached muscles. Frozen sections of the contents of the medullary canal at the level of bone division may help to confirm that it has been removed completely. ${ }^{5} \mathrm{~A}$ trial fitting of the prosthesis is carried out with the soft tissues brought together to avoid undue tissue tension, and the prosthesis is then cemented in place with a cement gun with an extra long nozzle. Finger packing of cement into the medullary cavity is inadequate. Muscle groups which have lost their attachments may be sewn to each other to give some useful muscle control. A prosthesis may be custom built to the requirements of an individual patient before surgery based on careful radiographic measurements of the skeleton so that the whole procedure of excision of the tumour and prosthetic replacement can be performed at one operation..$^{6}$ Alternatively a large number of prostheses of varying sizes can be held in stock. ${ }^{5}$

Replacement of the proximal femur with an endoprosthesis has been reported to give good functional and pain free results. ${ }^{7}$ Biomechanical evaluation including analysis of the gait and of the function of the hip muscles showed virtually normal patterns. ${ }^{8}$ Upper tibial tumours, however, are most difficult to replace, and the functional result less impressive, partly because of the difficulty in attaching the patella tendon to the prosthesis and partly because of the lack of surrounding tissues. No satisfactory total shoulder joint prosthesis has been developed; wide resection of the muscles around the shoulder usually precludes abduction, though patients in sedentary occupations may be able to use their hand for writing or typing.

Data are now available on both the long term failure rate of custom built endoprostheses and the effect of limb preserving surgery on the life expectancy of patients with bone tumours.
In a recent study of 81 patients with 88 replacements of the hip and proximal femur, Dobbs and others found that almost two thirds of those who survived 10 years retained their prostheses. ${ }^{9}$ The endoprosthetic stem fractured in half of the early prostheses made of cobalt chromium molybdenum alloy cast in one piece and attached to the bone with plates, nuts, and bolts, but no fracture was reported in 62 prostheses manufactured with a titanium alloy stem, though the average follow up at the time of publication was only 1.8 years. Two prostheses were removed for local recurrence of the tumour, and when these were excluded the 10 year survival of the prosthesis rose from $63 \%$ to $65 \%$, which is considerably better than that obtained for metal on metal total hip replacements $(56 \%)$ but not as successful as metal on plastic total hip replacements $(80 \%)$. The main cause of failure of standard total hip replacements was loosening of the prosthesis, but the upper femoral endoprosthesis was less affected owing to the greater length of the intramedullary stem fixed to healthy cortical bone at the midshaft region. If the problem of fractures of the stem of the upper femoral endoprosthesis could be overcome over $80 \%$, of replacements would be expected to survive for 10 years.

The 10 year survival probability of patients with chondrosarcoma treated by endoprosthetic replacement was $73^{\circ},{ }^{9}$ the worst survival being in those with pelvic tumours, ${ }^{10}$ and $90^{\circ} \%$ for patients with osteoclastoma. These values suggest that prosthetic replacement is as effective as wide local excision or amputation in these conditions.

Endoprosthetic replacement seems, therefore, to be the treatment of choice for bone tumours in a carefully selected group of patients for whom they offer improved quality of life with uncompromised longevity. To achieve these aims we must assess the biological behaviour of the tumour and the individual patient's needs and life expectancy.

Clinical Lecturer in Orthopaedic Surgery,

JoHN E Nixon

University of Oxford

Nuffield Orthopaedic Centre,

Oxford OX3 7LD

1 Harrington KD, Sim FH, Enis JE, Johnston JO, Dick HM, Gristina AG. Methylmethacrylate as an adjunct in internal fixation of pathological fractures: experience with three hundred and seventy-five cases. $\mathcal{F}$ Bone foint Surg 1976;58A : 1047-55.

2 Sim FH, Dougherty TW, Ivins JC. The adjunctive use of methylmethacrylate in fixation of pathological fractures. F Bone foint Surg 1974; 56A : $40-8$.

${ }^{3}$ Moore AT, Bohlman HR. Metal hip joint: a case report. 7 Bone foint Surg $1943 ; 25: 688-92$.

4 Sweetnam R. Limb preservation in the treatment of bone tumours. Ann $R$ Coll Surg Engl 1983;65:3-7.

5 Sim FH, Ivins JC, Pritchard DJ. Surgical treatment of osteogenic sarcoma at the Mayo clinic. Cancer Treat Rep 1978;62:205-11.

${ }^{6}$ Burrows HJ, Wilson JN, Scales JT. Excision of tumours of humerus and femur, with restoration by internal prostheses. F Bone foint Surg 1975 57B: 148-59.

' Johnston JO. Local resection in primary malignant bone tumors. Clin Orthop 1980;153:73-80.

* Sim FH, Chao EY. Biomechanical evaluation of proximal femur and custom hip joint replacement following segmental resection of bone tumors. F Bone foint Surg 1975;57A:565.

" Dobbs HS, Scales JT, Wilson JN, Kemp HBS, Burrows HJ, Sneath RS. Endoprosthetic replacement of the proximal femur and acetabulum: a survival analysis. $\mathcal{F}$ Bone foint Surg 1981 ;63B :219-24.

11 Marcove RC, Miké V, Hutter RVP, et al. Chondrosarcoma of the pelvis and upper end of the femur. An analysis of factors influencing survival time in one hundred and thirteen cases. F Bone foint Surg 1972;54A 561-72. 